\title{
Prevalence of communication disorders among school children in Ballari, South India: A cross-sectional study
}

\author{
Sunil Kumar Ravi *, P. Sumanth, T. Saraswathi, Mohammed Asif Basha Chinoor, N. Ashwini, \\ Ejaz Ahemed
}

Shravana Institute of Speech and Hearing, Ballari, Karnataka, India

\section{A R T I C L E I N F O}

\section{Keywords:}

Prevalence

Communication disorders

School children

Otological disorders

Hearing impairment

Speech disorders

Language disorders

\begin{abstract}
A B S T R A C T
Introduction: Congenital or acquired childhood communication disorders can negatively impact the emotional, social and academic skills in children. Research studies have reported that school going children are at higher risk of having communication disorders which will affect their academic and other skills. However, there is a dearth of studies on epidemiological data on communication disorders in school going children hence the present study was carried out to estimate the prevalence of communication disorders among school going children of Ballari district.

Method: In a Cross-sectional study carried out on 2304 school going children (6-16years) of primary and secondary government schools in rural areas of Ballari district, Karnataka were screened using subjective \& objective measures for communication disorders.

Results: The results revealed a total of 99 out of 2304 children were identified with communication disorders indicating a prevalence rate of $4.29 \%$. Among them, a total of 75 children were having hearing and otological disorders $(3.25 \%)$ and 24 children were having speech and language disorders $(1.04 \%)$. Further, the prevalence of communication disorders was found to be higher among males (2.38\%) compared to females $(1.91 \%)$.

Conclusion: The present study found a lesser prevalence rate of communication disorder in school aged children of Ballari district, than the previous studies. Hearing loss and otological problems such as impacted cerumen, ear pain, ear discharge, etc., were found to be more than speech-language disorders such as stuttering, speech sound disorders and child language disorders.
\end{abstract}

\section{Introduction}

Communication is the essence of human life to share or exchange messages, information, ideas or feelings through multiple modalities. ${ }^{1}$ Communication disorders refer to a wide range of "impairments in the ability to receive, send, process and comprehend concepts or verbal, nonverbal and graphic symbol systems". ${ }^{2}$ Communication disorder does not only affect the process of communication, but they result in disabling conditions for persons by affecting social and emotional well-being, cognition, and behaviors. ${ }^{3}$ Communication disorders can have adverse effects on various skills depending on the age and gender of individual, for example, communication disorders can affect the academic skills in childhood, followed by vocational skills later in adulthood. Communication disorders can be congenital or acquired and are caused due to impairments in speech, language and hearing abilities. ${ }^{2}$ Congenital or acquired childhood communication disorders can negatively impact the emotional, social and academic skills in children although to differential extents ${ }^{4,5},{ }^{6}$ Few of the common congenital communication disorders include developmental language disorders, intellectual disabilities, hearing impairments which have varied incidence and prevalence rates across different countries.

The incidence and prevalence rates of a disease or disorder will not only augment on understanding the disease across regions but also throw light on the etiology and factors involved in the disease progression. As per the Census of India 2011, ${ }^{7}$ the National Survey Sample Organization (NSSO) has reported a total of $2.21 \%$ of disabled population in India and among these, $18.9 \%$ were reported to have hearing impairment, $7.45 \%$ were reported to have speech impairments and $5.61 \%$ were reported to have mental retardation. Further, the data also shows that $69 \%$ of total disabled population was from rural areas while

\footnotetext{
* Corresponding author.

E-mail addresses: sunilkumar.ravi@aslp.org.in (S.K. Ravi), somuslpclinics@gmail.com (P. Sumanth), saraswathi.aslp@gmail.com (T. Saraswathi), asifaslp555@ gmail.com (M.A. Basha Chinoor), ashwiniaishu256@gmail.com (N. Ashwini), ejazahemed.ea@gmail.com (E. Ahemed).
} 
only $31 \%$ were from urban areas. However, as the NSSO data is based on survey research with informal questionnaire by non-professionals and the disability status was not validated by qualified professionals, the total population with disability may be much higher than reported.

Communication disorders are widely classified under speech, language, and hearing, disorders, which are reported to have higher prevalence rates in India. In a study conducted at rural areas of Karnataka, Konadath et al. ${ }^{8}$ reported higher prevalence rate $(6.07 \%)$ of communication disorders $(90.58 \%$ hearing disorders; $9.42 \%$ speech \& language disorders). Further, the authors have reported $6.8 \%$ of communication disorders were seen in children in the age range of 3-15 years. Similarly, in a study of rural population of Gujarat state, Sinha et al. ${ }^{9}$ reported a prevalence rate of $4.09 \%$ for communication disorders with $3.30 \%$ with ear-related disorders \& $0.79 \%$ with speech and language disorders. However, the prevalence rate of communication disorders was reported to be lesser (3.63\%) in Lakshadweep islands as reported by Konadath et al. ${ }^{10}$ with higher percentage of speech \& language disorders $(57.36 \%)$ compared to ear-related disorders $(42.64 \%)$. Jijo et al. ${ }^{11}$ have reported that consanguineous marriages $(20.78 \%)$, positive family history $(7.12 \%)$, delayed birth cry $(7.07 \%)$, and neonatal seizures $(5.86 \%)$ as major causative and risk factors associated with communication disorders in India.

Although the prevalence rates of congenital disorders are higher compared to acquired conditions, the unidentified acquired disorders such as middle ear pathologies, auditory processing disorders, learning difficulties can result in poor academic performance among school going children. ${ }^{12,13}$ Savithri et al. ${ }^{14}$ reported a prevalence rate of $14.2 \%$ (language disorders $=6.9 \%$; speech disorder $=3.7 \%$, hearing disorders $=3.4 \%$ \& multiple disorders $=0.3 \%$ ) among 1 st to 7 th grade children in a sample of 2010 school children of Mysore and Mandya districts of Karnataka. In a study on primary school children from Bikaner, Rajasthan, Ojha et al. ${ }^{15}$ reported a higher prevalence rate of $15.7 \%$ for hearing impairment. Similarly, Varsha et al. ${ }^{16}$ reported a prevalence rate of $8.94 \%$ among 1453 school children in the age range of 4-14 years in Chengalpattu district of Tamil Nadu with $58.46 \%$ having hearing impairments and $41.54 \%$ having speech \& language disorders. The results of the epidemiological studies indicated that the increased prevalence rates of communication disorders among school children is majorly due to presence of preventable otological conditions such as impacted cerumen, otitis media, fungal infections, and foreign body insertions which result in reduced hearing sensitivity as also reported by previous studies. ${ }^{17,18,19,20}$

The results of the above studies reported higher prevalence rate of communication disorders is among school children compared to overall prevalence rates ${ }^{8,9,10}$ however, this data is insufficient to understand the exact nature and causes of communication disorders among school children. Further, the majority of acquired communication disorders can be prevented through primary and secondary prevention programs to reduce the disease related burden. ${ }^{21}$ There is a great need to investigate the prevalence rates among school children in countries like India keeping the size and diversity of population. Hence, the present study was conducted to estimate the prevalence of communication disorders among school children from rural areas of Ballari district, Karnataka state.

\section{Methods}

\subsection{Participants}

In a cross-sectional study, a total of 2304 school going children (males $=1130$; females $=1174$ ) in the age range of 6 years -16 years were screened for communication disorders. All the children were from primary and secondary government schools in rural areas of Ballari district, Karnataka which were selected through a convenient sampling method and the demographic details of the participants are given in Table 1. All the children belonged to lower socioeconomic status as per
Table 1

Demographic data of children participated in the study.

\begin{tabular}{|c|c|c|c|c|c|c|c|}
\hline \multirow[t]{2}{*}{ Grade } & \multirow{2}{*}{$\begin{array}{l}\text { Total } \\
\text { number }\end{array}$} & \multicolumn{3}{|c|}{ Males } & \multicolumn{3}{|c|}{ Females } \\
\hline & & $\mathrm{N}$ & $\begin{array}{l}\text { Mean } \\
\text { Age }\end{array}$ & $\begin{array}{l}\text { SD } \\
\text { (age) }\end{array}$ & $\mathrm{N}$ & $\begin{array}{l}\text { Mean } \\
\text { Age }\end{array}$ & $\begin{array}{l}\text { SD } \\
\text { (age) }\end{array}$ \\
\hline $\begin{array}{l}\text { 10th } \\
\text { grade }\end{array}$ & 214 & 121 & 15.75 & 0.85 & 93 & 15.62 & 0.65 \\
\hline $\begin{array}{l}\text { 9th } \\
\text { grade }\end{array}$ & 236 & 145 & 15.08 & 0.69 & 91 & 14.59 & 0.79 \\
\hline $\begin{array}{l}\text { 8th } \\
\text { grade }\end{array}$ & 278 & 115 & 13.86 & 0.45 & 163 & 13.73 & 0.61 \\
\hline $\begin{array}{l}\text { 7th } \\
\text { grade }\end{array}$ & 309 & 149 & 12.99 & 0.46 & 160 & 12.87 & 0.54 \\
\hline $\begin{array}{l}\text { 6th } \\
\text { grade }\end{array}$ & 259 & 116 & 12.04 & 0.41 & 143 & 11.91 & 0.42 \\
\hline $\begin{array}{l}5 \text { th } \\
\text { grade }\end{array}$ & 195 & 98 & 10.90 & 0.78 & 97 & 10.75 & 0.56 \\
\hline $\begin{array}{l}\text { 4th } \\
\text { grade }\end{array}$ & 235 & 113 & 9.96 & 1.04 & 122 & 10.00 & 0.37 \\
\hline $\begin{array}{l}\text { 3rd } \\
\text { grade }\end{array}$ & 217 & 105 & 8.78 & 0.49 & 112 & 8.59 & 0.51 \\
\hline $\begin{array}{l}\text { 2nd } \\
\text { grade }\end{array}$ & 184 & 83 & 7.41 & 0.49 & 101 & 8.07 & 1.31 \\
\hline $\begin{array}{l}\text { 1st } \\
\text { grade }\end{array}$ & 177 & 85 & 6.28 & 0.45 & 92 & 6.29 & 0.54 \\
\hline
\end{tabular}

the data available with school authorities and the screening for communication disorders was carried out between the months of July 2019 and January 2020 after obtaining ethical approval from the IEC (No.SISH/IEC/Approval/11) and prior consent from school authorities.

\subsection{Procedure}

Each child was screened individually with otoscopic examination, audiological evaluation and speech-language screening for presence of communication disorders. The otoscopic examination and audiological evaluation was carried out in a school with minimum background noise levels after conducting biological subjective calibration through subjective listening check procedure on normal individuals. Otoscopic examination was done to identify the presence of ear wax, ear perforation and other abnormalities of ear canal and tympanic membrane. Audiological evaluation included pure-tone audiometry (PTA) testing using ALPS AD2100 audiometer to obtain air conduction thresholds at $250 \mathrm{~Hz}$, $500 \mathrm{~Hz}, 1 \mathrm{KHz}, 2 \mathrm{KHz}, 4 \mathrm{KHz}$ and $8 \mathrm{KHz}$ and bone conduction thresholds at $250 \mathrm{~Hz}, 500 \mathrm{~Hz}, 1 \mathrm{KHz}, 2 \mathrm{KHz}, 4 \mathrm{KHz}$. Pure-tone average of $500 \mathrm{~Hz}, 1$ $\mathrm{KHz}$ and $2 \mathrm{KHz}$ were measured for each ear and degree of hearing loss was determined using the classification of hearing loss given by Clark. ${ }^{22}$ Any child having pure tone average of $26 \mathrm{~dB}$ or above in any one ear or both ears were categorized as failed in screening. Those children with pure tone average of $16-25 \mathrm{~dB}$ (slight hearing loss) were asked for a follow-up after three months as the PTA was conducted in an informal settings and not in a standard audiometric room.

Speech and language screening was carried out for presence of any impairments in oromotor abilities, language, fluency, articulation and voice domains using formal and informal assessment procedures using narration, picture description and general conversation tasks. The criteria (Appendix-1) for screening communication disorders among school children was developed based on the norms of the standard developmental checklists and test batteries such as Communication DEALL Developmental Checklist, ${ }^{23}$ Assessment of oromotor skills, ${ }^{24}$ Stuttering Severity Instrument - Fourth Edition, ${ }^{25}$ Kannada Diagnostic Photo Articulation Test, ${ }^{26}$ GRBAS Perceptual Voice Rating Scale ${ }^{27}$ and the criteria as per Diagnostic and Statistical Manual of Mental Disorders - 5th Edition. ${ }^{28}$ Parents of all the children failed in screening were counseled regarding the identified impairments and were referred for detailed evaluations. The data obtained from screening was entered into MS-Office Excel sheets and were analyzed using IBM SPSS v20.0 $0^{29}$ to calculate the percentage of prevalence of communication disorders 
across gender and grades.

\section{Results}

\subsection{Prevalence of communication disorders among school children}

A total of 2304 school children were screened for presence of communication disorders in Ballari district for estimating the point prevalence rates of hearing \& otological disorders, speech and language disorders. Hearing screening was done using pure tone audiometry and the data collected for each ear for primary, higher primary and high school children for males and females were analyzed for mean and standard deviation and the results are given in Table 2. The data was tested for normality using Shapiro-wilk test of normality and the data was found to be non-normally distributed and this may be due to the fact that the hearing sensitivity range of humans vary from $-10 \mathrm{~dB}$ to 120 dB. A chi-squared test results revealed no significant association between gender and communication disorders $\left[\mathrm{X}^{2}{ }_{(1)}=0.735, \mathrm{p}>0.05\right]$. Further, the chi-square test results also revealed no association between grade and communication disorders $\left[\mathrm{X}^{2}{ }_{(2)}=4.526, \mathrm{p}>0.05\right]$.

A total of 99 (4.29\%) children were identified with communication disorders. Among 99 children, 55 (55.55\%) were male children and 44 $(44.44 \%)$ were female children. A total of 75 children (males $=38$, females $=37$ ) were having hearing loss and otological problems such as impacted cerumen, ear pain, ear discharge, etc., and 24 children (males $=17 \&$ females $=07$ ) were found to have speech and language disorders such as stuttering, voice disorders, speech sound disorders and child language disorders. The percentage of hearing, speech and language disorders for each grade are given in Table 3.

\subsection{Prevalence of hearing and otological disorders among school children}

A total of 75 children (3.25\%) were identified to have hearing and otological disorders out of total 2304 children. Among these 75 children, 53 children $(70.66 \%)$ had otological problems such as impacted cerumen, ear pain, ear discharge, retracted tympanic membrane and atresia along with hearing loss while remaining 22 children $(29.33 \%)$ only had conductive $(n=6)$, sensorineural $(n=9)$ and mixed hearing loss $(n=7)$. The Audiological evaluation of the children revealed presence of mild to moderate levels of hearing loss of various types. Among the 75 children with otological disorders and hearing loss, four children had unilateral hearing loss while remaining children had bilateral hearing loss. Grade wise number of children having otological and hearing disorders across genders is given in Table 4.

Table 2

Mean and Standard deviation of PTA and results of normality test for each group.

\begin{tabular}{|c|c|c|c|c|c|}
\hline \multirow[t]{2}{*}{ Group } & & \multicolumn{2}{|c|}{ Right Ear } & \multicolumn{2}{|c|}{ Left Ear } \\
\hline & & $\begin{array}{l}\text { Mean } \\
\pm \mathrm{SD}\end{array}$ & $\begin{array}{l}\text { Shapiro-Wilk } \\
\text { Test of } \\
\text { Normality }\end{array}$ & $\begin{array}{l}\text { Mean } \\
\pm \text { SD }\end{array}$ & $\begin{array}{l}\text { Shapiro-Wilk } \\
\text { Test of } \\
\text { Normality }\end{array}$ \\
\hline \multirow[t]{3}{*}{ Males } & Primary & $\begin{array}{l}15.77 \\
\pm 3.39\end{array}$ & $.948 *$ & $\begin{array}{l}15.42 \\
\pm 3.68\end{array}$ & $.935^{*}$ \\
\hline & $\begin{array}{l}\text { Higher } \\
\text { Primary }\end{array}$ & $\begin{array}{l}14.91 \\
\pm 3.76\end{array}$ & $.973^{*}$ & $\begin{array}{l}14.36 \\
\pm 3.90\end{array}$ & $.971 *$ \\
\hline & $\begin{array}{l}\text { High } \\
\text { School }\end{array}$ & $\begin{array}{l}12.53 \\
\pm 3.74\end{array}$ & $.977 *$ & $\begin{array}{l}12.48 \\
\pm 4.61\end{array}$ & $.805^{*}$ \\
\hline \multirow[t]{3}{*}{ Females } & Primary & $\begin{array}{l}15.74 \\
\pm 3.59\end{array}$ & $.55^{*}$ & $\begin{array}{l}15.09 \\
\pm 3.20\end{array}$ & $.962 *$ \\
\hline & $\begin{array}{l}\text { Higher } \\
\text { Primary }\end{array}$ & $\begin{array}{l}13.87 \\
\pm 3.58\end{array}$ & $.941 *$ & $\begin{array}{l}13.53 \\
\pm 3.61\end{array}$ & $.947^{*}$ \\
\hline & $\begin{array}{l}\text { High } \\
\text { School }\end{array}$ & $\begin{array}{l}13.47 \\
\pm 4.32\end{array}$ & $.964 *$ & $\begin{array}{l}13.28 \\
\pm 4.79\end{array}$ & $.914 *$ \\
\hline
\end{tabular}

$*: p<0.05$.

\subsection{Prevalence of speech and language disorders}

A total of 24 children (1.04\%) out of total 2304 school children were identified to have speech and language disorders. Among 24 children, 14 children (males $=10 \&$ females $=4$ ) had speech disorders such as stuttering $(\mathrm{n}=5)$, voice disorders $(\mathrm{n}=2)$, and speech sound disorders $(\mathrm{n}=7)$ while remaining 10 children (males $=07 \&$ females $=03$ ) had language disorders such as developmental language disorders $(n=7)$ including those children with hearing impairment, and specific learning disorder $(n=3)$.

\section{Discussion}

In the present study, a total of 99 children out of 2304 children were identified with communication disorders indicating a prevalence rate of $4.29 \%$ among school children with higher percentage of communication disorders in primary grade $(23.67 \%)$ children compared to higher primary grade (8.94\%) and high school (14.0\%) children. Further, a total of 75 children were having hearing and otological disorders with a prevalence rate of $3.25 \%$ and 24 children were having speech and language disorders with a prevalence rate of $1.04 \%$. This may be attributed to otological disorders among children due to poor hygiene, the lack of awareness, literacy levels, socioeconomic status, lack of clinical facilities, etc among rural areas. ${ }^{11,17-20}$ Further, the prevalence of communication disorders was higher among males (2.38\%) compared to females $(1.91 \%)$ which may be due to differences in the developmental patterns of speech and language, ${ }^{30}$ genetic and non-genetic factors where females are prone to overcome few of the developmental speech disorders such as stuttering ${ }^{31,32,33}$ higher prevalence of otological conditions (trauma, middle ear infections, etc.) in males than females. $8,10,14,16$

The results of the present study revealed lesser prevalence rates (4.29\%) of communication disorders among school children in Ballari district as compared to the previous studies ${ }^{14,15,}{ }^{16}$ The lower prevalence rate of communication disorders may be due to the differences in methods used where the present study included a elaborated audiological screening and speech \& language evaluation of all the participants in contrast to screening procedures by the previous studies ${ }^{14,15,16}$ The lower prevalence rate of communication disorders among school children revealed by the present study is also may be due to the fact that the participants were from only six schools of Ballari district which may not be the true representative sample of entire district.

The present study results revealed a total of 75 (3.25\%) children with hearing and otological problems which is similar to the study by Savithri et al. ${ }^{14}$ which reported $3.4 \%$ of prevalence rate for hearing disorders among school children and also a study by Varsha et al. ${ }^{16}$ who reported presence of hearing and otological problems in 85 children among 1453 school children. Further, among the 75 children with hearing and otological problems, $53(2.30 \%)$ children were having otological problems such as impacted curemen, perforation, ear pain, etc which is lesser in contrast to the findings of previous studies by Chadha et al., ${ }^{18}$ who reported a prevalence rate of $17.92 \%$ among school children in northern India and also a study by Parvez et al. ${ }^{20}$ who reported a prevalence rate of $17.9 \%$ among school children of Aligarh district. Further, the prevalence rates of hearing disorders was also lower compared to the study by Ojha et al. ${ }^{15}$ who reported a prevalence rate of $15.7 \%$ for hearing impairment in school children in the age range of 3-14 years. The higher otological and hearing problems among school children may be due to lack of awareness about ear and hearing care, poor hygiene among rural population, socio-economic status, etc, which may be prevented through early identification and treatment. ${ }^{20}$ Otological impairments are more frequent seasonal (rainy \& winter) weather changes, may be leading to common middle ear pathologies in the school children, ${ }^{34}$ especially among children from rural areas due to poor hygiene, lack of awareness and socioeconomic issues. ${ }^{17,18,19,35}$

A total of 24 children (1.04\%) out of total 2304 school children were 
Table 3

Prevalence of communication disorders (hearing, speech and language disorders) among school children.

\begin{tabular}{|c|c|c|c|c|c|c|c|c|}
\hline \multirow[t]{2}{*}{ Grade } & \multicolumn{2}{|c|}{ Hearing problems } & \multicolumn{2}{|c|}{ Speech disorders } & \multicolumn{2}{|c|}{ Language disorders } & \multicolumn{2}{|l|}{ Total } \\
\hline & Males & Females & Males & Females & Males & Females & Males & Females \\
\hline 10th grade & $1.65 \%$ & $6.45 \%$ & $0.82 \%$ & 0 & 0 & 0 & $2.47 \%$ & $6.45 \%$ \\
\hline 9th grade & $7.58 \%$ & $5.49 \%$ & $1.37 \%$ & $1.09 \%$ & 0 & 0 & $8.96 \%$ & $6.59 \%$ \\
\hline 8th grade & $1.73 \%$ & $1.84 \%$ & 0 & 0 & 0 & 0 & $1.70 \%$ & $1.84 \%$ \\
\hline 7 th grade & 0 & $2.50 \%$ & $1.34 \%$ & 0 & 0 & 0 & $1.34 \%$ & $2.50 \%$ \\
\hline 6 th grade & $3.44 \%$ & $1.39 \%$ & 0 & 0 & 0 & 0 & $3.44 \%$ & $1.39 \%$ \\
\hline 5 th grade & $4.08 \%$ & $3.09 \%$ & $1.02 \%$ & 0 & $1.02 \%$ & 0 & $6.12 \%$ & $3.09 \%$ \\
\hline 4 th grade & $1.76 \%$ & 0 & 0 & $1.63 \%$ & 0 & 0 & $1.76 \%$ & $1.63 \%$ \\
\hline 3rd grade & $2.85 \%$ & $4.46 \%$ & 0 & 0 & $0.95 \%$ & 0 & $3.80 \%$ & $4.09 \%$ \\
\hline 2nd grade & $4.81 \%$ & $4.95 \%$ & 0 & 0 & $2.4 \%$ & $0.99 \%$ & $7.24 \%$ & $5.94 \%$ \\
\hline 1 st grade & $7.05 \%$ & $4.34 \%$ & $4.70 \%$ & $1.08 \%$ & $3.52 \%$ & $2.17 \%$ & $15.29 \%$ & $7.60 \%$ \\
\hline Mean & $3.36 \%$ & $3.15 \%$ & $0.88 \%$ & $0.34 \%$ & $0.61 \%$ & $0.25 \%$ & $4.86 \%$ & $3.74 \%$ \\
\hline
\end{tabular}

Table 4

Grade-wise number of children having otological and hearing problems.

\begin{tabular}{|c|c|c|c|c|c|c|c|c|}
\hline \multirow[t]{2}{*}{ Grade } & \multicolumn{2}{|c|}{ Otological problems } & \multicolumn{2}{|c|}{ Conductive hearing loss } & \multicolumn{2}{|c|}{ Sensorineural hearing loss } & \multicolumn{2}{|c|}{ Mixed hearing loss } \\
\hline & Males & Females & Males & Females & Males & Females & Males & Females \\
\hline 10th grade & 1 & 3 & 0 & 3 & 0 & 0 & 1 & 0 \\
\hline 9th grade & 5 & 3 & 4 & 1 & 1 & 0 & 1 & 1 \\
\hline 8th grade & 2 & 1 & 0 & 1 & 0 & 1 & 0 & 0 \\
\hline 7 th grade & 0 & 4 & 0 & 2 & 0 & 0 & 0 & 1 \\
\hline 6 th grade & 2 & 1 & 2 & 1 & 0 & 0 & 0 & 0 \\
\hline 5 th grade & 3 & 2 & 3 & 3 & 1 & 0 & 0 & 0 \\
\hline 4th grade & 0 & 3 & 1 & 1 & 1 & 0 & 0 & 0 \\
\hline 3rd grade & 3 & 2 & 1 & 2 & 1 & 1 & 0 & 1 \\
\hline 2nd grade & 3 & 6 & 2 & 2 & 0 & 0 & 1 & 0 \\
\hline 1st grade & 4 & 5 & 2 & 3 & 1 & 2 & 1 & 0 \\
\hline
\end{tabular}

identified to have speech and language disorders which is lesser in contrast to the prevalence rate of $10.6 \%$ reported by Savithri et al. ${ }^{14}$ and $3.09 \%$ by Varsha et al. ${ }^{16}$ The present study revealed stuttering and speech sound disorders are more prevalent among school children compared to other speech and language disorders. The majority of developmental language disorders in school children were due to the presence of impairments in sensory, functional and intellectual abilities with poorer access to the rehabilitative services, poor modeling and reinforcement by teachers \& parents ${ }^{14}$ and certain sensory loss can also affect academic the performances of children. ${ }^{3,36}$ Although the present study highlighted the prevalence of communication disorders through a detailed screening for various communication disorders as mentioned in Appendix-1, the study did not analyze the risk factors among the children with communication disorders.

\section{Conclusions}

The present study was carried out to investigate the prevalence of communication disorders among school children in rural areas of Ballari district, Karnataka. A detailed screening for various communication disorders was conducted for a total of 2304 school children and the results revealed a prevalence rate of $4.29 \%$ with higher prevalence for hearing disorders $(3.25 \%)$ compared to speech \& language disorders (1.04\%). Further, the results of the present study revealed higher percentage of otological diseases such as impacted cerumen, otitis media, fungal infections probably due to poor hygiene which can be prevented through early identification and management. Although, the prevalence rate of the present study are lesser than the previous studies, more studies are warranted to explore the prevalence of communication disorders among school children from different parts of India and explore the impact of various factors associated with communication disorders in school children. The epidemiological data on the frequency, distribution, causative factors will help government and non-government organizations to conduct awareness programs for parents and teachers, plan early identification and treatment programs for school going children which will enhance the holistic performance.

\section{Funding}

This research did not receive any specific grant from funding agencies in the public, commercial, or not-for-profit sectors.

\section{Author contributions}

Conceptualization: SKR, ST, MABC

Data curation: SKR, ST, MABC, AN, EA

Methodology: SKR, ST, MABC, AN, EA

Project administration: SKR, ST

Visualization: SKR, SP, ST, EA

Writing original draft: SKR, SP, MABC

Writing - review \& editing: SKR, SP

\section{Declaration of competing interest}

The authors have no conflict of interest associated with the material presented in this paper.

\section{Acknowledgement}

Authors thank Chairman, Shravana Institute of Speech and Hearing, Ballari for permitting to carry out the research. Sincere gratitude is extended to the following students for contributing in data collection: Varsha B N, Sai Samyuktha V, Ph Rahamani, A Shivani, Shabnam, Jinsha M.K, Jahnavi K.P, Prashdina M, Geethu M, Rakshitha SR, Rajaganapathi, and Akshay Mysore. Authors extend sincere thanks to the School authorities for permitting us to collect the data. 


\section{Appendix 1}

Criteria used for screening for communication disorders among school children.

\begin{tabular}{|c|c|c|}
\hline Domain & Pass/Fail & Criteria \\
\hline \multirow[t]{2}{*}{ Hearing Screening } & Pass & Pure tone average of $25 \mathrm{~dB}$ or less in both ears \\
\hline & Fail & Pure tone average of $26 \mathrm{~dB}$ or more in any one or both ears \\
\hline \multirow[t]{2}{*}{ Otoscopy } & Pass & Normal external ear structures and tympanic membrane \\
\hline & Fail & Any structural abnormality of external ear or abnormality in tympanic membrane \\
\hline \multirow[t]{2}{*}{ Fluency disorder } & Pass & Less than $5 \%$ dysfluencies in speech (min. of 100 word sample) \\
\hline & Fail & More than $5 \%$ dysfluencies in speech (min. of 100 word sample) \\
\hline \multirow[t]{2}{*}{ Voice disorder } & Pass & Rating of GOROBOAOSO on GRBAS Scale \\
\hline & Fail & Rating of G1R1B1A1S1 or above on GRBAS Scale \\
\hline \multirow[t]{2}{*}{ Speech Sound disorder } & Pass & PCC $>80 \%$ \\
\hline & Fail & PCC $<80 \%$ \\
\hline \multirow[t]{2}{*}{ Speech intelligibility } & Pass & Rating of 0 or 1 on AYJNIHH Speech Intelligbility Rating Scale \\
\hline & Fail & Rating of 2 or above on AYJNIHH Speech Intelligbility Rating Scale \\
\hline \multirow[t]{2}{*}{ Language disorders } & Pass & Age adequate semantic, syntactic and pragmatic skills \\
\hline & Fail & Delay or deviancy in semantic or syntactic or pragmatic skills \\
\hline \multirow[t]{2}{*}{ Reading \& writing difficulties } & Pass & No difficulty in reading and writing skill \\
\hline & Fail & Presence of reading and writing difficulty, (ex. Spelling errors on dictation, etc.) \\
\hline \multirow[t]{2}{*}{ Oromotor skills } & Pass & Normal structure and functioning of all oral structures such as lips, jaw, teeth, tongue, hard palate and soft palate \\
\hline & Fail & Any structural or functional abnormalities or poor oral dynamics. \\
\hline
\end{tabular}

\section{References}

1 Hulit LM, Howard MR. Born to Talk. third ed. Boston: Allyn and Bacon; 2002.

2 American Speech-Language-Hearing Association. Definitions of Communication. Disorders and Variations. 1993.

3 McKinnon DH, McLeod S, Reilly S. The prevalence of stuttering, voice, and speechsound disorders in primary school students in Australia. Lang Speech Hear Serv Sch. 2007;38(1):5-15.

4 Lewis BA, Freebirn LA, Taylor HG. Academic outcomes in children with histories of speech sound disorders. J Comm Dis. 2000;33(1):11-30.

5 Eide ER, Showalter MH, Goldhaber DD. The relation between children's health and academic achievement. Child Youth Serv. 2010;32(2):231-238.

6 Nelson KE, Welsh JA, Trup EM, Greenberg MT. Language delays of impoverished preschool children in relation to early academic and recognition skills. First Lang. 2011;31(2):164-194.

7 Ministry of Statistics and Programme Implementation, Government of India. Disabled Persons in India A Statistical Profile; 2016. www.mospi.gov.

8 Konadath S, Suma C, Jayaram G, Sandeep M, Mahima G, Shreyank PS. Prevalence of communication disorders in a rural population of India. J Hear Sci. 2013;3(2):41-49.

9 Sinha SK, Shivaswamy J, Barman A, Seth D, Seshadri D, Savithri SR. Prevalence of communication disorders in a rural population at taluq level of Gujarat, India. Clin. Epidemiol. Glob. Heal. 2017;5(2):73-78.

10 Konadath S, Chatni S, Lakshmi MS, Saini JK. Prevalence of communication disorders in a group of islands in India. Clin Epidemiol Glob Heal. 2017;5(2):79-86.

11 Jijo PM, Sreeraj K, Sandhya K, Preethi M, Rashmi P. Prevalence and causes of communication disorders- A retrospective study from northern Karnataka. Clin Epidemiol Glob Heal. 2020;8(1):138-141.

12 Paul AK. Early identification of hearing loss and centralized newborn hearing screening facility-the Cochin experience. Indian Pediatr. 2011;48(5):355-359.

13 Wetherby A, Prizant B. Toward earlier identification of communication and language problems in infants and young children. New visions for the developmental assessment of infants and young children. 1996:289-312.

14 Savithri SR, Barman A, Shanbal JC. School Screening: Distribution of Communication Disorders in School Children. Mysore: All India Institute of Speech and Hearing; 2015.

15 Ojha M, Kumar S, Nandurkar A. Hearing screening in primary school children: an overview. Int J Com Health Med Res. 2016;2(2):23-31.

16 Varsha NS, Sowmiya R, Prasitha P, Praveena J. Prevalence of speech language and hearing impairment in school going children of rural area: a longitudinal study. Int $J$ Com Med Pub Heal. 2020;7(10):4043-4047.

17 Shaheen MM, Raquib A, Ahmad SM. Prevalence and associated socio-demographic factors of chronic suppurative otitis media among rural primary school children of Bangladesh. Int J Pediatr Otorhinolaryngol. 2012;76(8):1201-1204.
18 Chadha SK, Sayal A, Malhotra V, Agarwal AK. Prevalence of preventable ear disorders in over 15,000 schoolchildren in northern India. J Laryngol Otol. 2013;127 (1):28-32.

19 Shankar NR, Dev MS, Geethachary. A study of the prevalence of ear diseases in school children of rural Tumkur district, Karnataka. J Evol Med Dent Sci. 2015;32(4): 5506-5511.

20 Parvez A, Siddiui A, Khan Z, Hasmi S, Khan M. Prevalence of hearing impairment among primary school children in rural and urban areas of Aligarh, Uttar Pradesh, India. Int J Com Med Public Heal. 2016;3(5):1273-1277.

21 Chadha SK, Gulati K, Garg S, Agarwal AK. Prevalence of ear diseases in the children of Delhi. J Laryngol Otol. 2015;129(5):425-429.

22 Clark JG. Uses and abuses of hearing loss classification. ASHA. 1981;23(7):493-500.

23 Karanth P. Communication DEALL Developmental Checklists. Bangalore: The Com DEALL Trust; 2007.

24 Archana G, Karanth P. Assessment of the Oromotor Skills in Toddlers. Bangalore: The Com DEALL trust; 2008.

25 Riley G. Stuttering Severity Instrument -. fourth ed. Texas: Pro-ed; 2009.

26 Anand D, Savithri SR. Kannada Diagnostic Photo Articulation Test (2-6 Years). Mysore: All India Institute of Speech and Hearing Publications; 2012.

27 Hirano M. Psycho-acoustic Evaluation of Voice. New York: Springer-Verlag; 1981.

28 American Psychiatric Association. Diagnostic and Statistical Manual of Menta Disorders: DSM-5. Washington, DC: American psychiatric association; 2013.

29 IBM Corp. IBM SPSS Statistics for Windows, Version 20.0. Armonk, NY: IBM Corp; 2011.

30 Sommer M, Waltersbacher A, Schlotmann A, Schröder H, Strzelczyk A. Prevalence and therapy rates for stuttering, cluttering, and developmental disorders of speech and language: evaluation of German health insurance data. Front. human neurosci. 2021;15:176.

31 Yairi E, Ambrose N, Cox N. Genetics of stuttering: a critical review. J Speech Lang Hear Res. 1996;39:771-784.

32 Ambrose NG, Cox NJ, Yairi A. The genetic basis of persistence and recovery in stuttering. J Speech Lang Hear Res. 1997;40:567-580.

33 Yairi E, Ambrose N. Epidemiology of stuttering: 21st century advances. J Fluen Disord. 2013;38:66-87.

34 Harlor AD, Bower C. Hearing assessment in infants and children: recommendations beyond neonatal screening. Pediatrics. 2009;124(4):1252-1263.

35 Nogueira JC, da Conceição Mendonça M. Assessment of hearing in a municipal public school student population. Braz J Otorhinolaryngol. 2011;77(6):716-720.

36 Elbeltagy R. Prevalence of mild hearing loss in schoolchildren and its association with their school performance. Int Arch Otorhinolaryngol. 2020;24(1):E93-E98. 